\title{
EGU2020-18
}

https://doi.org/10.5194/egusphere-egu2020-18

EGU General Assembly 2020

(c) Author(s) 2020. This work is distributed under

the Creative Commons Attribution 4.0 License.

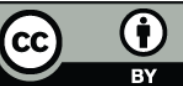

\section{Minimizing biodiversity trade-offs of future global hydropower reservoirs by strategic site selection}

\author{
Martin Dorber ${ }^{1}$, Anders Arvesen ${ }^{1}$, David Gernaat ${ }^{2,3}$, and Francesca Verones ${ }^{1}$ \\ ${ }^{1}$ Industrial Ecology Programme, Norwegian University of Science and Technology, Norway (martin.dorber@ntnu.no) \\ ${ }^{2} \mathrm{PBL}$ - Netherlands Environment Assessment Agency, The Hague, The Netherlands \\ ${ }^{3}$ Copernicus Institute of Sustainable Development, Utrecht University, Utrecht, The Netherlands
}

The Sustainable Development Goals (SDG) require increased hydropower electricity production to reach SDG 7. However, a balance between related positive synergies and negative trade-offs needs to be found. So far there has been a strong focus on the technical development potential (SDG 7), and the positive synergies of hydropower, for example in relation to SDG 13 (Climate change). However, hydropower can also cause, for instance, biodiversity impacts, leading to a negative biodiversity trade-off with SDG 6 (Clean water and sanitation) and SDG 15 (Life on land). Although conservation of biodiversity has been identified as a key parameter for sustainable development, global assessments accounting for site specific biodiversity trade-offs of hydropower sites are still lacking.

To fill this research gap, we performed the first global and reservoir explicit assessment of terrestrial and aquatic biodiversity impacts of 2000 possible future hydropower reservoirs. We adapted the latest spatially explicit impact assessment methods available from the field of life cycle assessment, with a high-resolution and location-specific technical assessment of future economic hydropower potentials (Gernaat et al., Nature Energy 2017). More specially we collected site-specific environmental information from geographic information system databases to quantify potential reservoir-specific, net land occupation, net water consumption and methane emissions. Subsequently, we quantified the related terrestrial and aquatic biodiversity impact in units of potentially disappeared fraction of species (PDF).

Our results show that future hydropower electricity production can have a spatially highly variable biodiversity impact (varying by orders of magnitude) which can interfere with SDG 6 and SDG 15. Furthermore, we show that careful selection of reservoirs on a macro level has a large potential to limit biodiversity impacts. Thus, sustainable hydropower development requires an assessment of potential biodiversity impacts. This in turn means, that if mitigating climate change for SDG 13 is the main motivation for increased hydropower production, as it can score favorable in studies comparing GHG emissions, it is likely that potential biodiversity impacts are overlooked. However, in order to move towards overall sustainability, taking biodiversity impacts into account next to climate change and other impacts, is of utmost importance. 
How to cite: Dorber, M., Arvesen, A., Gernaat, D., and Verones, F.: Minimizing biodiversity tradeoffs of future global hydropower reservoirs by strategic site selection, EGU General Assembly 2020, Online, 4-8 May 2020, EGU2020-18, https://doi.org/10.5194/egusphere-egu2020-18, 2019 